\title{
EFFECT OF REPEAT PURCHASE AND DYNAMIC MARKET SIZE ON DIFFUSION OF AN INNOVATIVE TECHNOLOGICAL CONSUMER PRODUCT IN A SEGMENTED MARKET
}

\author{
Sugandha AGGARWAL a , Anshu GUPTA ${ }^{\mathrm{a}, \mathrm{b}}$, Kannan GOVINDAN', \\ P. C. JHA ${ }^{\mathrm{a}}$, Ieva MEIDUTE் \\ a Department of Operational Research, University of Delhi, Delhi, India \\ ${ }^{b}$ SBPPSE, Dr. B. R. Ambedkar University, Delhi, India \\ 'Department of Business and Economics, University of Southern Denmark, Denmark \\ ${ }^{\mathrm{d} D e p a r t m e n t ~ o f ~ B u s i n e s s ~ M a n a g e m e n t, ~ V i l n i u s ~ G e d i m i n a s ~ T e c h n i c a l ~ U n i v e r s i t y, ~}$ \\ Sauletekio al. 11, 10223 Vilnius, Lithuania
}

Received 07 April 2013; accepted 30 June 2013

\begin{abstract}
This study develops diffusion models for technological consumer products under the marketing environment when a product is marketed in a segmented market and observes two distinctive promotional strategies of mass and differentiated promotion; an under explored study area. Mass promotion strategy creates a spectrum effect in market with an aim to create wider product awareness and influence the market size. Whereas the differentiated promotion strategy plays major role in external influence component in the respective segment and target for adoption by the current potential segment. Previous studies on segmented diffusion models assumed only first time purchase and constant market size which may yield underestimated results and fail to give appropriate insight of the diffusion process. The study develops and validates generalized diffusion models for segmented market incorporating the repurchase behaviour of the adopter population and dynamic potential market size considerations. Performance of the proposed models is analysed on real life data for a new product marketed in four segments and compared with the previous study.
\end{abstract}

Keywords: adoption growth, product life cycle, repeat purchase, dynamic market size, promotion strategy, spectrum effect.

Reference to this paper should be made as follows: Aggarwal, S.; Gupta, A.; Govindan, K.; Jha, P. C.; Meidute, I. 2014. Effect of repeat purchase and dynamic market size on diffusion of an innovative technological consumer product in a segmented market, Technological and Economic Development of Economy 20(1): 97-115.

JEL Classification: O31, M31, M39, M51.

Corresponding author Kannan Govindan

E-mail:gov@sam.sdu.dk 


\section{Introduction}

\section{Research background}

New product development is the locus of innovative potential of an organization. The competitive success of a firm depends largely on its capability to develop new products. Driven by the globalization of markets, technological advances and ever changing customer needs; continuous innovation and development of an ecosystem of whole range of new products has become a vital part of an organization's business practices (Schimmoeller 2010). The rate of technological changes has largely accelerated the development of new product innovations based on newer technologies and shortened the product life cycles in the last two decades (Ismail et al. 2012). Organization dedicate huge amount of human, material, technological and monetary resources on the development of new products. Yet the new products continue to fail at an alarming rate due to many reasons. The biggest problem identified behind the huge new product failures is the lack of timely and adequate analysis and preparedness to market the products (Schneider, Hall 2011). With the quest for successful product introductions, organizations constantly look for the methods and techniques for innovation, new product development and marketing.

Innovation, new product development and their successful marketing is a widely studied area in the literature. The academic and business periodical literature is replete with detailed research on the various aspects of this process. Some of the widely studied aspects in this area include studies related to the market research on the requirement and acceptance of new products in markets (Sawng et al. 2011; Foulquie et al. 2004), consumer behaviour and new product development (Tolba, Mourad 2011; Sawng et al. 2011; Renko, Janakiraman 2008), innovation, technologies and new product development (Kock et al. 2011; Shane et al. 2004; Kim et al. 2011), market performance (Schimmoeller 2010; Ismail et al. 2012; Schneider, Hall 2011; Jayaram, Narasimhan 2007), marketing products (Ozer, Cebeci 2010), product life cycle, and time factors (Jha et al. 2006; Aggarwal et al. 2012; Bayus et al. 1997, Calantone, Benedetto 2000), successive generations of technological products (Danaher et al. 2001; Foulquie et al. 2004) and many more. The requirement of closely analysing the market performance of new products, that how the product acceptability grows in the potential market over their product life cycle is a research area which has grown tremendously (Meade, Islam 2006) and is continuously growing due to ever changing markets, marketing paradigms and consumer empowerment. This study concentrates on this particular aspect of new product development and proposes new mathematical models for predicting and analysing the adoption growth of a technological consumer product. The proposed models are applicable for describing the adoption behaviour of technological consumer products with respect to joint effect of mass and differentiated market promotion in a segmented market over the product life cycle considering two different marketing scenarios. First scenario describes the adoption under the possibilities of repeat adoption behaviour while second scenario analyses dynamic nature of market potential over time. The marketing environments under consideration have been looked for the first time in such a study to the best of our knowledge. 
The theory of diffusion of innovation has developed across many fields of research over the past several decades (Rogers 1983). While the study of diffusion originated in sociology and anthropology, marketing and consumer behaviour theorists have adopted the general paradigm for use in their fields to explain new product acceptability and diffusion over time. One of the important factors which make a new product successful in the market is building an understanding about how an innovation diffuses (diffusion process) within its target population and measuring it over its life cycle. A diffusion model describes the adoption characteristics, explains the mechanism, and assists in predicting how a new product will diffuse in market. Selection of an appropriate diffusion model to determine the diffusion pattern and main factors influencing the rate and timing of a successful adoption of innovation is vital to business firms for developing optimal marketing strategies that help them increase the competitiveness of product and the firm itself. In spite of several innovation diffusion models developed in the literature over the past several decades, no model can be called as general, which could be used for any product and in any marketing environment. The main reason for this fact is the ever changing and growing marketing environment. The changing marketing environment necessitates development of the new innovation diffusion models that can well describe the adoption behaviour for the recent and future marketing environments. The diffusion models proposed in this study have been developed for a marketing environment faced by many of today's business organizations and has been tested on real life situation.

Most of the earlier literature on the diffusion of technological consumer products describes the growth of product considering the market as a whole. The product diffusion is captured either with respect to time, or promotional efforts assuming that all consumers are alike and product is marketed with a common promotional strategy. These models describe the external influence due to mass media and internal influence due to word of mouth. In current marketing scenario the market of the product is often segmented based on differential profile of the consumers so as to better position the product in the market. Segmentation allows firms to target the product specifically to the different consumer groups by adopting promotional strategies keeping in mind the differential characteristic of the segments. Diffusion model which ignores the effect of segmentation on the adoption growth are not applicable to estimate and predict the adoption behaviour when the market observes a differentiated external influence due to segmented promotional strategies; as the results obtained using them can be very far from the reality. Diffusion of innovation in segmented market is a research area explored very limitedly in the literature. We propose here some diffusion models in this area by extending the work done due to Jha et al. (2014). The models are developed considering a marketing environment, which is different from the previous study, and are applicable to wider marketing situations. More discussion on this is carried in the later sections after the literature review.

\section{Literature review}

Main focus of the diffusion models in marketing is on communication channels by which the information about an innovation is transmitted in passage of time to the social systems, considering two distinct influences - internal influence resulting from word-of-mouth 
communication and external influence represented by the mass media (Mahajan et al. 1990). The literature on new product diffusion growth modelling is large-spread. While the preliminary studies focused mainly on modelling the adoption process with respect to communication channels and found successful implementation in the real life cases (Bass 1969; Easingwood et al. 1983; Horsky, Simon 1983). Later, as the marketing paradigms and environment changed, the researches in the field studied the diverse and changing aspects of the process. The studies attempted to offer generalizations concerning models and incorporate decision variables and their effects on diffusion patterns (Mahajan et al. 2000; Meade, Islam 2006; Hauser et al. 2006; Chandrasekaran, Tellis 2007; Krishnan, Suman 2009; Renana et al. 2010). Earlier studies developed models which addressed either pure external influence or internal influence. Bass (1969) model was the mixed influence model and was widely accepted due to its flexible nature and ability to describe both pure external and internal influence situations. The model categorized the adopter population into two groups: innovators and imitators respectively. Innovators population adopt through external influences, whereas imitators adoption is influenced by the innovators opinion. Succeedingly several studies focus on the development of mixed influence innovation diffusion models under diverse marketing environment and assumptions (Horsky, Simon 1983, 1990; Jain, Rao 1990; Jain 1990; Jones, Ritz 1991; Kalish 1985; Mahajan, Peterson 1978, 1985). Some models attempted to combine the effects with traditional economic variables such as price and advertising in the diffusion modelling (Russell 1980). Bass along with other researchers (Bass et al. 1994) developed a Generalized Bass Model (GBM) to describe the adoption growth with respect to current marketing efforts. Various other factors such as diffusion channels (Jones, Ritz 1991; Rangaswamy, Gupta 2000), competition (Kauffman, Techatassanasoontorn 2005; Van den Bulte, Stremersch 2004), technology update (Bass, P., Bass, F. M. 2004; Kim et al. 2000), repeat purchase (Steffens 2002), indirect network externality (Gupta et al. 1999) were also added to Bass model for its improvement and expansion. Consumers' different preferences on price (Bridges et al. 1995), risk (Chatterjee, Eliashberg 1990), brand (Libai et al. 2009), etc. affecting diffusion of products were also studied.

Some scholars compared the new product diffusion caused by technological update to innovation diffusion in single technology, they considered that diffusion of technology updates can increase market potential and reflect the impact of consumer heterogeneity (Goldenberg, Oreg 2007; Mahajan, Muller 1996). Early studies only focused on word of mouth, that is, communication between consumers, but exchanges between consumers are also affected by its host network which was done through the study of network externalities (Stremersch et al. 2001), network information (Van den Bulte, Stremersch 2004), and network structure (Kossinets, Watts 2006). Some research also considers the spatial diffusion of innovation and not just diffusion over time. For example, there is a research about cross product diffusion in different cultural resources (Redmond 1994) or different economic resources (Desiraju et al. 2004). Steffens (1998) investigated cross-country heterogeneity and studied the intra-country variations using priori segmentation schemes, namely geographic segmentation. Bohlmann et al. (2010) examined the effects of various network structures and relational heterogeneity on innovation diffusion within market networks. 


\section{Research motivation}

Promotion is a very crucial component of the marketing mix that attracts attention, stirs up interest, creates desire, assures belief, and impels action; action to buy the product. Since promotion is a dominant marketing mix variable, the effects of other marketing mix variables can be assumed at a constant level. The pioneering model of innovation diffusion, due to Bass (1969) and various later models, describes the adoption growth with respect to time. Firms are rather interested to capture the adoption growth with respect to promotional efforts carried to market the product. Innovation diffusion models given by Jha et al. (2006) describe the adoption behaviour focusing on the internal and external influences with respect to promotional efforts under different market environments. The model retained the mathematical nature of the Bass model due to the property that it has a flexible form and can describe different types of adoption growth curves but simultaneously generalized the model by eliminating some of its limiting assumptions (restricted to apply in the situation of only first time purchase and constant market size). However, due to growing economies, national as well as global markets and growing heterogeneity of consumer groups, these models find limited application and are not suitable to reflect the appropriate adoption behaviour when the product is marketed in a segmented market. Market segmentation is an important marketing strategy followed by most of the marketers of new products. Consumer is the most powerful entity in the present market, segmentation of market allows firms to serve its customers keeping in mind their differential characteristics. By segmenting the market while marketing a product, the product is positioned differentially in each segment so as to influence each segment differently, according to the segment characteristics and thereby generating higher product growth. As stated earlier, models of innovation diffusion besides marketing variables focus mainly on the communication channels, and the communication channel influences are extremely different in case of segmented market as compared to the mass market. The models due to Bass (Bass 1969; Bass et al. 1994) and its generalizations considered the market as a whole and describe sales growth considering the external influence due to mass media and internal influence due to word of mouth. These models are not applicable effectively to estimate and predict the adoption behaviour when the market observes a differentiated external influence due to segmented promotional strategies.

Different consumer segments have different behaviour towards the new product and they respond distinctly for the promotional activities, therefore, the rate of adoption vary across segments. Thus, it becomes important to study how the new product diffuses in different market segments under the effect of segmented promotional efforts. A segmented market often observes two different forms of promotion viz. mass promotion and differentiated promotion. Mass promotion addresses the whole potential market assuming all customers alike. The mass promotion strategy is implemented using the promotional vehicles for wider awareness such as national television. Mass promotion targets larger audiences in all segments of the market and creates a spectrum effect in the market leading to wider product awareness and increased market potential (Burrato et al. 2006). Differentiated promotion is carried out by targeting individual segments through distinct promotional strategies. Here, promotional planning is tailored according to the consumer characteristics and promotional 
vehicle preferences for each segment (Berry, Wilson 2001; Rao 2011; Egan 2007). Both forms of promotions have their unique importance, the mass promotion along with influencing diffusion, focuses on creating product awareness in a larger market and influencing the total market potential size over time. On the other hand, differentiated market promotion targets the respective segments market potential towards adoption.

One of the recent studies Jha et al. (2014) caters to this particular marketing environment with some major limitations. An innovation diffusion model is developed by the authors for technological consumer product assuming that the product diffuses in each segment due to the combined influence of mass promotion and differentiated promotion along with the internal influence factors. Although the model describes the adoption growth with respect to the differential promotional effort in segments along with mass promotion, but the model applicability is constrained due to the assumptions that it captures only the first time purchases and assumes that the eventual market potential is constant (remains same throughout the product life cycle). However, in real marketing scenario repeat purchasing is an important phenomenon and can't be ignored. Traditionally, it is coined as one of the five phases (last) of product adoption viz. awareness, interest evaluation, trial, and adoption (Rogers 1983). The adoption phase incorporates consumers' adoptability towards the product and his/ her propensity to repurchase the product. Along with this market potential of a product as determined in the initial phase of product launch doesn't remain constant but grows as the product diffuses in the market due to various factors such as widespread awareness of the product, increase in purchasing power of the consumers, population growth and economic reasons. Using an innovation diffusion model developed with these restricted assumptions to predict the product adoption can provide underestimated results and mayn't provide appropriate insight into the product diffusion process. Decisions made using these results may divert the firms from reality. It necessitates the development of diffusion model which not only describes the adoption growth in the segmented marketed under differentiated and mass promotion strategy, but also associates the repeat purchase behaviour and dynamic nature of market potential in the model. In this paper two generalized new innovation diffusion models are proposed, by dropping the assumption of only first time purchases and constant market size and developing mathematical relationships to incorporate repeat purchase and dynamic market size under the joint impact of differentiated promotion and spectrum effect of mass promotion. The proposed models are applicable for a wider marketing environment as compared to the previous study.

\section{Distinguished features of the study}

- The proposed models are developed for a marketing environment which has been explored very rarely in the literature of the very important study area of innovation diffusion in marketing.

- The model finds application for analysing how a new product diffuses in a segmented market which observes two different forms of promotion viz., mass and differentiated promotion. The impact of external influence on adoption is captured under the joint influence of both types of promotions. 
- Earlier model in this category considered constant market size throughout the planning period and only first time sales for describing the adoption growth, which can give underestimated growth curves. The proposed model first time analyses, the dynamic size of market potential and repeat purchase behaviour in a segmented market.

- The model apart from the other known applications of diffusion modelling in marketing such as promotion allocation, adopter categorization, timing of new product introductions, etc. also finds application for many other marketing decision making such as segment wise effectiveness of mass and differentiated promotion, deciding on the optimal resource distribution for mass and differentiated promotion, segment wise market potential growth and repeat purchase parameters.

- The model is tested in a real life case.

The paper is organized as follows. Section 1 describes the mathematical development of the proposed models. Section 2 presents the validity of the model for a real marketing case and shows the estimation of parameters for proposed models with results and discussion. The final section concludes the paper.

\section{Model development}

Notations:

$i \quad$ Segment index; $i=1,2, \ldots K$

$\bar{N}, \bar{N}_{i}(t)$ Expected potential adopter population in the $i^{t h}$ segment of the market (at time $t$ )

$p_{i} \quad$ Parameter representing external influence in $i^{\text {th }}$ segment

$q_{i} \quad$ Parameter representing internal influence in $i^{\text {th }}$ segment

$b_{i} \quad$ Sum of coefficients of external influence and internal influence in $i^{\text {th }}$ segment; $\left(b_{i}=p_{i}+q_{i}\right)$

$\beta_{i} \quad$ Ratio of coefficient of internal influence to external influence in $i^{\text {th }}$ segment; $\left(\beta_{i}=q_{i} / p_{i}\right)$

$x_{i}(t) \quad$ Rate of promotional effort at time $t$ in the $i^{t h}$ segment of the market; $X_{i}(t)=\int_{0}^{t} x_{i}(u) d u$

$X_{i} \quad$ Promotional resources allocated for differentiated market promotion in $i^{\text {th }}$ segment

X Promotional resources allocated for mass market promotion

Z Total promotional budget available

$N_{i}(t) \quad$ Expected number of adopters of the product in the $i^{t h}$ segment of the market by time $t$. 
The proposed model uses basic mathematical structure of Jha et al. (2014) sales growth model considering its flexible mathematical form and applicability. The model describes external as well as internal influence so that its mathematical structure becomes even more useful for us to use it as a basic building block for the development of our models.

Model assumptions:

1. The adoption process is binary.

2. The market can be segmented into $k$ distinct segments.

3. Each purchaser buys a single unit of the product.

4. The size of the potential adopter population remains constant throughout of the product life cycle as determined in the beginning of the adoption process.

5. The adoption process grows over time due to both external and internal influences.

6. The parameters of external and internal influences are fixed over the diffusion process of the innovation.

7. The rate of adoption at any time $t$ with respect to promotional efforts is proportional to the remaining number of adopters in the segment.

8. The adoption is influenced both due to mass and differentiated promotional efforts.

The differential equation of the Jha et al. (2014) model for the $i^{\text {th }}$ segment is given as:

$$
\frac{\frac{d}{d t} N_{i}(t)}{\left(x_{i}(t)+\alpha_{i} x(t)\right)}=\left(p_{i}+q_{i} \frac{N_{i}(t)}{\bar{N}_{i}}\right)\left(\bar{N}_{i}-N_{i}(t)\right), i=1,2, \ldots, K \text {. }
$$

Under the initial conditions $N_{i}(t)=0, X_{i}(t)=0, X(t)=0$ at $t=0$ the model is described by the following equation:

$$
N_{i}\left(X_{i}(t), X(t)\right)=\frac{\bar{N}_{i}\left(1-e^{-\left(p_{i}+q_{i}\right)\left(X_{i}(t)+\alpha_{i} X(t)\right)}\right)}{\left(1+\left(\frac{q_{i}}{p_{i}} e^{-\left(p_{i}+q_{i}\right)\left(X_{i}(t)+\alpha_{i} X(t)\right)}\right)\right)}, i=1,2, \ldots, K .
$$

Equation (1) can be written alternately by changing the mathematical form of the rate of adoption per remaining adopters denoted by $b(t)$ given as:

$$
b(t)=b /\left(1+\beta e^{-b t}\right) .
$$

The diffusion model (1) can be derived alternatively as:

$$
\frac{\frac{d}{d t} N_{i}(t)}{\left(x_{i}(t)+\alpha_{i} x(t)\right)}=\frac{b_{i}}{1+\beta_{i} e^{-b_{i} t}}\left(\bar{N}_{i}-N_{i}(t)\right), i=1,2, \ldots, K,
$$

which can be solved under same initial conditions to give the form:

$$
N_{i}\left(X_{i}(t), X(t)\right)=\frac{\bar{N}_{i}\left(1-e^{-b_{i}\left(X_{i}(t)+\alpha_{i} X(t)\right)}\right)}{\left(1+\left(\beta_{i} e^{-b_{i}\left(X_{i}(t)+\alpha_{i} X(t)\right)}\right)\right)}, i=1,2, \ldots, K .
$$


Sibstituting $\beta_{i}=q_{i} / p_{i}$ and $b_{i}=p_{i}+q_{i}$ it can be observed that the Equation (5) is identical to model (2). The alternative derivation (4) is necessary for the development of the proposed model. Model generalization based on the Equation (2) can't be solved for exact solution. However if the model is derived using the differential Equation (4), exact solution can be obtained for the proposed model maintaining the basic structure and assumptions of the model (2).

\subsection{Repeat purchase model}

In this section, we develop a diffusion model for describing the diffusion of a new technological consumer product due to both external and internal influences in a segmented market considering repeat purchase with respect to the joint effect of mass and differentiated promotion. Repeat purchasing is an important real life phenomenon; the existing adopters often repurchase the same product. Thus the increase in sales of the product may not be alone through first purchase but it also includes some proportion of repeat purchasers which a firm might always be interested in knowing. Thus, here we relax the assumption that each purchaser buys only a single unit of the product and generalize the model (5) for the case when some adopters of the product adopt more than one unit of the product.

The additional assumptions of the proposed repeat purchase model excluding the assumption (3) above are:

1. The successive increase in the number of adopters may consist of first time buyers as well as repeat buyers of an innovation.

2. At any given instant of time $t, g_{i}\left(0<g_{i}<1\right)$ proportion of total adoption is susceptible to repeat purchasing in each segment.

3. Repeat purchasing is influenced by all factors (both internal and external) affecting first purchase.

The differential equation for the rate of adoption of the product in $i^{\text {th }}$ segment considering repeat purchase with respect to the promotional effort (mass and differentiated) is formulated as follows:

$$
\frac{\frac{d}{d t} N_{i}(t)}{\left(x_{i}(t)+\alpha_{i} x(t)\right)}=b_{i}(t)\left(\bar{N}_{i}-\left(1-g_{i}\right) N_{i}(t)\right), i=1,2, \ldots, K,
$$

where: $b_{i}(t)=\frac{b_{i}}{1+\beta_{i} e^{-b_{i}\left(X_{i}(t)+\alpha_{i} X(t)\right)}}, i=1,2, \ldots, K$.

The expected number of adopters in the interval $(0, t]$ in the $i^{\text {th }}$ egment after solving (6) under the initial conditions $N_{i}(t)=0, X_{i}(t)=0, X(t)=0$ at $t=0$ is obtained as:

$$
N_{i}\left(X_{i}(t), X(t)\right)=\frac{\bar{N}_{i}}{1-g_{i}}\left[1-\left\{\frac{\left(1+\beta_{i}\right) e^{-b_{i}\left(X_{i}(t)+\alpha_{i} X(t)\right)}}{1+\beta_{i} e^{-b_{i}\left(X_{i}(t)+\alpha_{i} X(t)\right)}}\right\}^{1-g_{i}}\right], i=1,2, \ldots, K .
$$

The model M1 can be used to illustrate the adoption growth in the $i^{\text {th }}$ segment of the potential market. 


\subsection{Dynamic market potential model}

This section shows the development of the diffusion model for a new technological consumer product due to both external and internal influences in a segmented market considering the dynamic nature of the market potential for every segment with respect to the joint effect of mass and differentiated promotion. It is an important point to note here that the promotional activities not only influence the adoption behaviour of the potential consumers, but also influence the size of the market potential over time. In the beginning of the product life cycle, i.e. at the time of introduction of the product, the estimated size of the potential adopter population can be less, either due to unawareness or poor estimation due to unavailability of actual adoption data. As the product reaches the market, it is expected that with rise in product awareness, promotion and internal influences a larger potential consumer group will be created. Many other factors plays role here in influencing the size of the market potential such as increase in the purchasing power of the consumer. Assumption (4) of the Jha et al. (2014) model may result in giving an underestimated diffusion of the product. Thus, it is very important for a diffusion model to allow the market size to change with time. Therefore, we drop the assumption (4) above and develop the differential equation for the model under the assumption that the expected cumulative market potential at any time $t$, in the product life cycle is $\bar{N}_{i}(t)$, which is function of time. Further discussion on the nature of $\bar{N}_{i}(t)$ is carried after the development of the model.

The adoption rate equation modifies as follows:

$$
\frac{\frac{d}{d t} N_{i}(t)}{\left(x_{i}(t)+\alpha_{i} x(t)\right)}=\frac{b_{i}}{1+\beta_{i} e^{-b_{i} t}}\left(\bar{N}_{i}(t)-N_{i}(t)\right), i=1,2, \ldots, K .
$$

We consider two different forms of $\bar{N}_{i}(t)$ according to the nature of growth of the potential market size. Putting these forms in Equation (7) and solving under the initial conditions $N_{i}(t)=0, X_{i}(t)=0, X(t)=0$ at $t=0$ we get solutions as given below in Table 1.

Table 1. Different forms of $\bar{N}_{i}(t)$ d diffusion models using these forms

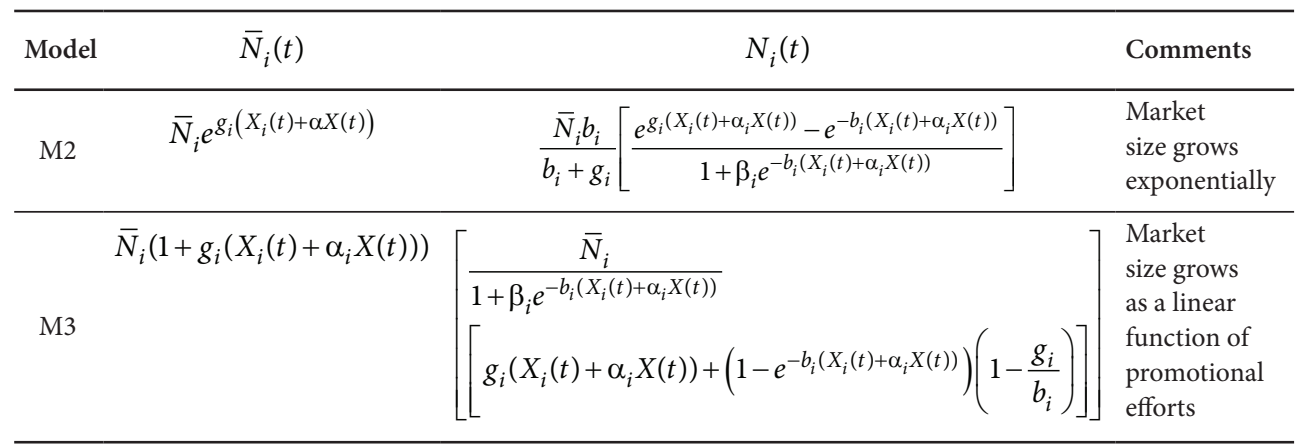

The exact nature of $\bar{N}_{i}(t)$ depends upon the social system and marketing environment. 


\section{Model validity and application}

To test the validity and measure the performance of the proposed models, we performed parameter estimation on data cited in Jha et al. (2014) of a new hatchback car of an ABC automobile company evolved through mass and differentiated promotion. The data cited in Jha et al. (2014) is chosen primarily to compare the performance of the proposed models with this model as the proposed models are generalizations for their model. Using this data the parameters of the proposed models are estimated and the estimates of adoption for the observed and future period are obtained to test the models and measure their performance as compared to the Jha et al. (2014) model (results taken from the study). The mathematical structure of proposed as well as the model chosen for comparative analysis are non-linear in nature. The method of non-linear regression applies for the estimation of parameters of nonlinear mathematical models. It is very difficult and time consuming to obtain the estimates using non-linear regression manually. Various support software are available, which can be used for the purpose that would provide solution with high accuracy. Here we have used the non-linear regression function of the software SPSS to estimate unknown parameters of the model. SPSS is statistical software package widely used for quantitative research and has gained popularity as it is easy to learn, offers full range of data management system and editing tools, provides full range of statistical capabilities and is widely tested for accuracy of results. It allows exporting the data from many different types of file formats.

A model's applicability is determined by its ability of fitness on the data used for analysis. In the literature, various methods and criteria are proposed to establish the goodness of fit of a model depending on the type of model. The goodness of fit of the proposed models is established using the criteria mean square error (MSE) and coefficient of multiple determination $\left(R^{2}\right)$.

\subsection{Data analysis}

Unknown estimates of the proposed models (M1, M2 and M3) using the 24-period sales data in four distinct market segments are obtained using the software support SPSS. The estimated parameter values for the proposed and tha et al. (2014) models are given in Table 2. Columns 8 and 9 of Table 2 list the MSE and $R^{2}$ values for all models in each segment. The goodness of fit curves for all the four segments are illustrated in Figures 1(a)-1(d), 2(a)-2(d) and $3(\mathrm{a})-3(\mathrm{~d})$. The curves also show the further projection of adoption for the next six months.

Table 2. Estimation results for the proposed models

\begin{tabular}{ccccccccc}
\hline \multirow{2}{*}{ Model } & \multirow{3}{*}{ Segments } & \multicolumn{4}{c}{ Parameter estimates } & \multicolumn{2}{c}{ Fit statistics } \\
\cline { 2 - 9 } & & $\bar{N}_{i}$ & $b_{i}$ & $\beta_{i}$ & $g_{i}$ & $\alpha_{i}$ & MSE & $R^{2}$ \\
\hline \multirow{3}{*}{ M1 } & S1 & 279107 & 0.138370 & 179.63 & 0.0500 & 0.300 & 191467.00 & 0.98113 \\
\cline { 2 - 9 } & $\mathrm{S} 2$ & 152460 & 0.481736 & 414.08 & 0.0265 & 0.190 & 13753.13 & 0.98111 \\
\cline { 2 - 9 } & $\mathrm{S} 3$ & 97581 & 0.541775 & 391.56 & 0.0878 & 0.189 & 11146.31 & 0.98332 \\
\cline { 2 - 9 } & $\mathrm{S} 4$ & 215868 & 0.314169 & 571.61 & 0.0476 & 0.321 & 168077.37 & 0.97696 \\
\hline
\end{tabular}


Continued Table 2

\begin{tabular}{|c|c|c|c|c|c|c|c|c|}
\hline \multirow{2}{*}{ Model } & \multirow{2}{*}{ Segments } & \multicolumn{5}{|c|}{ Parameter estimates } & \multicolumn{2}{|c|}{ Fit statistics } \\
\hline & & $\bar{N}_{i}$ & $b_{i}$ & $\beta_{i}$ & $g_{i}$ & $\alpha_{i}$ & MSE & $R^{2}$ \\
\hline \multirow{4}{*}{ M2 } & S1 & 41330 & 0.123077 & 31.70 & 0.0453 & 0.339 & 1128.17 & 0.99864 \\
\hline & S2 & 66633 & 0.428514 & 176.76 & 0.0662 & 0.200 & 5690.43 & 0.99989 \\
\hline & S3 & 57232 & 0.476789 & 220.09 & 0.0509 & 0.213 & 8144.91 & 0.98786 \\
\hline & S4 & 162318 & 0.336248 & 396.09 & 0.0150 & 0.240 & 143545.00 & 0.97876 \\
\hline \multirow{4}{*}{ M3 } & S1 & 98435 & 0.116946 & 58.51 & 0.0597 & 0.25 & 59571.97 & 0.99824 \\
\hline & S2 & 94427 & 0.445413 & 259.51 & 0.0500 & 0.20 & 7242.82 & 0.98632 \\
\hline & S3 & 50631 & 0.481654 & 208.54 & 0.0964 & 0.20 & 5787.91 & 0.98734 \\
\hline & S4 & 154853 & 0.296856 & 399.71 & 0.0202 & 0.33 & 113393.58 & 0.97992 \\
\hline \multirow{4}{*}{$\begin{array}{c}\text { Jha et al. } \\
(2014)\end{array}$} & S1 & 287962 & 0.132784 & 196.89 & - & 0.373 & 196105.50 & 0.98513 \\
\hline & S2 & 156601 & 0.471786 & 417.25 & - & 0.198 & 13832.28 & 0.99426 \\
\hline & S3 & 106977 & 0.56738 & 421.16 & - & 0.166 & 11994.30 & 0.98225 \\
\hline & S4 & 223291 & 0.332286 & 534.08 & - & 0.264 & 173423.70 & 0.98355 \\
\hline
\end{tabular}

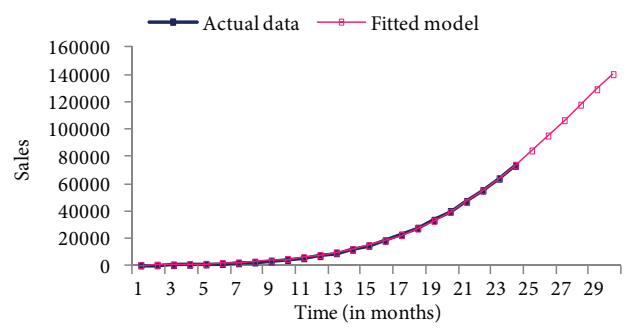

Fig. 1(a). Goodness of fit curve of segment 1 for M1

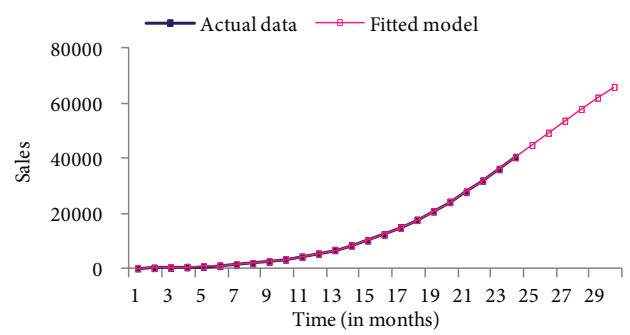

Fig. 1(c). Goodness of fit curve of segment 3 for M1

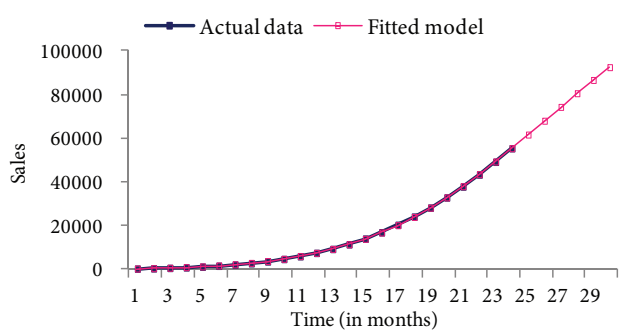

Fig. 1(b). Goodness of fit curve of segment 2 for M1

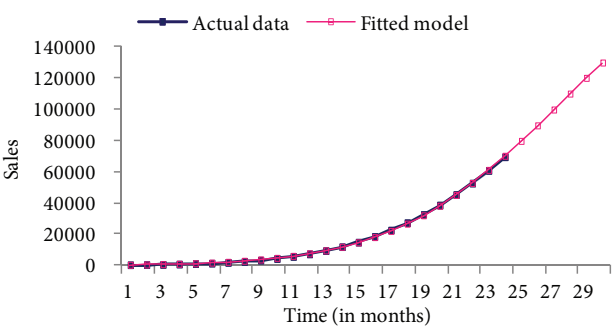

Fig. 1(d). Goodness of fit curve of segment 4 for M1 


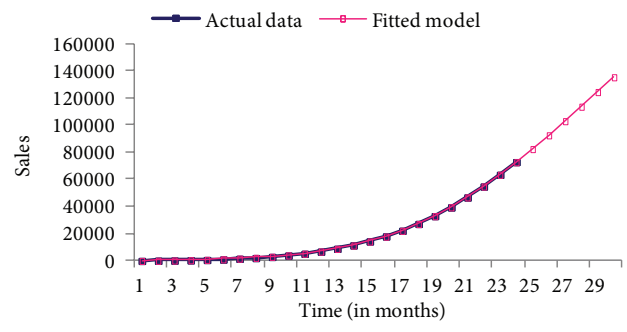

Fig. 2(a). Goodness of fit curve of segment 1 for M2

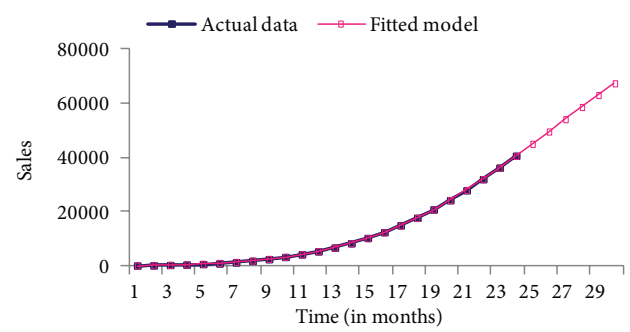

Fig. 2(c). Goodness of fit curve of segment 3 for M2

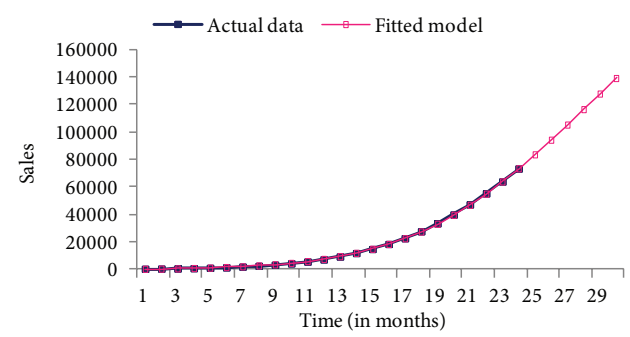

Fig. 3(a). Goodness of fit curve of segment 1 for M3

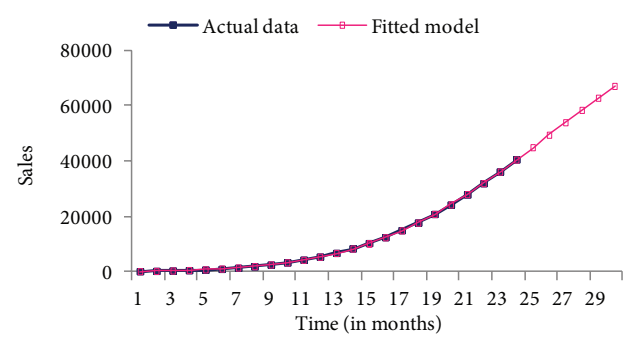

Fig. 3(c). Goodness of fit curve of segment 3 for M3

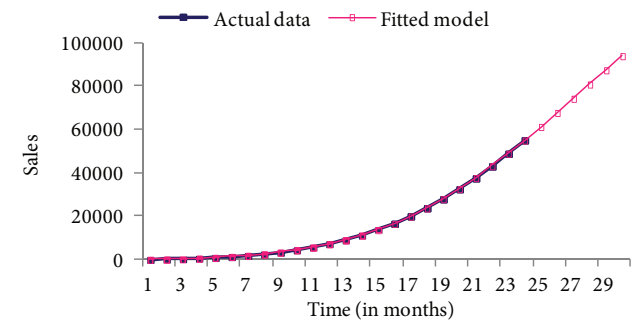

Fig. 2(b). Goodness of fit curve of segment 2 for M2

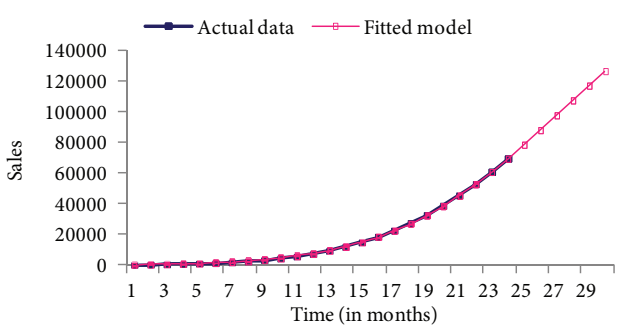

Fig. 2(d). Goodness of fit curve of segment 4 for M2

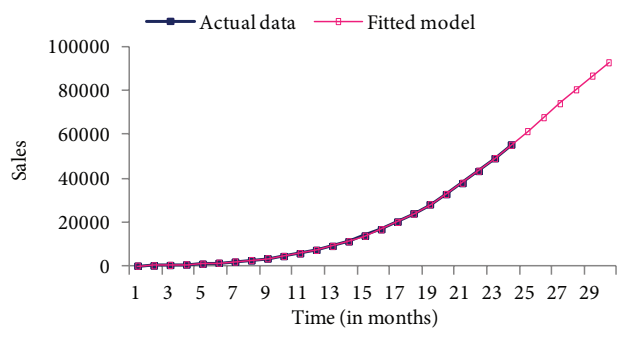

Fig. 3(b). Goodness of fit curve of segment 2 for M3

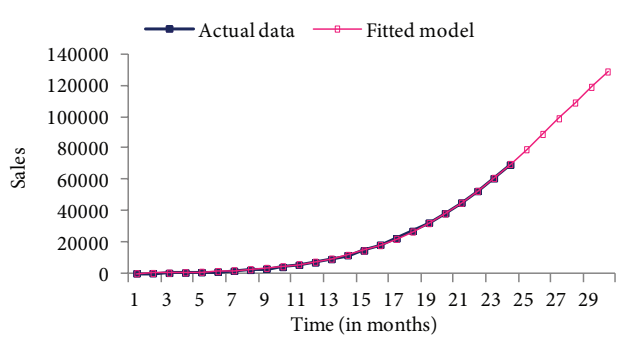

Fig. 3(d). Goodness of fit curve of segment 4 for M3 


\subsection{Results and discussion}

Table 2 summarizes the results of parameter estimation. If we talk in terms of the model which fits best to this data set from Table 2, it can be seen that dynamic market size models best describe the adoption growth for this product. Model M2 fits best in segments S1 and S2, while model M3 fits best in segments S3 and S4 with lower value of MSE and $R^{2}$. Model M2 describes the growth in the adopter potential with an exponential growth curve while the model M3 describes the market potential growth as a linear function of promotional efforts. As different segments have differential characteristics, so it is quite expected that the nature of growth in market potential in the segments can vary. We have explored only these two forms, however, one may also use other growth curves for the purpose. In this case, the practitioner can choose the model M2 for forecasting the adoption of product over its life cycle for segments S1 and S2 and model M3 in case of segments S3 and S4.

As the segments are heterogeneous and consumer group of one segment shows some unique characteristics as compared to other segments, hence, not only the nature of growth in potential market size shows different nature but also a product may assimilate quickly in one segment as compared to other. Increase in potential segment size can also be different as the time progresses; it can be high in one segment and lower in another. It corresponds exactly to our analysis that different forms of $\bar{N}_{i}(t)$ fit the data and the parameter of growth $\left(\mathrm{g}_{\mathrm{i}}\right)$ also varies between the segments. The product under consideration is a high value product and in the analysis the parameter $g_{i}$ takes value between 0.2 to 0.9 for the best fit segments.

Although the repeat purchase model (M1) is not among the best fit but gives better fit than Jha et al. (2014) model. MSE obtained on fitting the actual data on the proposed models comes out to be lower than Jha et al. (2014) model. The data taken for analysis is for a car's adoption behaviour, so very low repurchase behaviour (2-9\%) is observed for the product as expected. The repurchase behaviour is an adoption characteristic more applicable to consumable product but it can't be overlooked for the case of technological consumer durable products. Firms always look for the loyal customers as they act as the strong pillars for internal influence component of the product adoption. Repurchase behaviour is important for technological consumer products for one more and a very different reason, in case of technological products new versions/regenerations hit the market at a faster rate and often at the time of repurchase a consumer may find a newer version of the product in the market. The decision to adopt the newer version from the same marketer shows consumers' loyalty for the firm's products. The measurement of loyal population helps the firm in estimating the initial size of the potential segment for the new products of the same firm.

The analysis brings forward a very important result. The column 3 of Table 2 lists the size of potential segment as estimated in the beginning of the product life cycle. Jha et al. (2014) model gives the highest value of potential population size in all the segments. These estimates are nearest to the repeat purchase model. The difference accounts for the repeater population in the segments. However, in case of dynamic market size model the difference is quite wider, for example, the initial market size for segments in case of model M2 as compared to Jha et al. (2014) model is only $14.35 \%, 42.55 \%, 53.50 \%$ and $72.69 \%$ respectively. The similar 
results are obtained in case of model M3 and Jha et al. (2014) $(34.18 \%, 60.30 \%, 47.33 \%$ and $69.35 \%)$ model. This is due to the fact that in real marketing situations the size of the potential segments is usually low in the early launch period which eventually rises as the product awareness grows, by the means of both external and internal influence. The estimation of the size of the potential population is very useful in decisions related to promotional strategy. An overestimated value may lead to inappropriate promotional policy formulation and reduce the effectiveness of promotion.

The proposed models also give an estimate of contribution of the mass promotion on the total adoption. For example, the mass promotion accounts for $30 \%$ contribution in case of model M1 for segment S1. This means $70 \%$ adoption in this segment is due to the differential promotional strategy and 30\% comes from the spectrum effect of mass promotion.

The study and the results of analysis open a number of further study areas in the field.

Here the developed models address repeat purchase and dynamic market size separately. One may find the immediate need to develop a model which can simultaneously capture both phenomena. However, an attempt to develop such a model makes the differential equation very complicated and difficult to solve for exact solution. It needs a different structural formulation. Further scholars might look for how to analyse the impact of price change, competition, older and newer versions, etc. on the diffusions of the product under consideration. Timing study for the new product version launch and similar study for the consumable goods can also be performed for the marketing environment under consideration.

\section{Conclusions}

Our study has developed diffusion models to describe the effect of external-internal influences on adoption in marketing scenario when a product is marketed in segmented market under the combined influence of mass and differentiated promotion. Most of the existing models in the literature assume absence of segmentation while developing the model and if used for prediction the adoption behaviour for a product marketed in segmented market mayn't provide appropriate results.

The proposed model also generalizes the assumptions of the existing few studies in the marketing environment under consideration. An important characteristic of the proposed models is their ability to capture the repeat purchase behaviour and dynamic size of market potential in the diffusion process. The model validity and performance has been tested in a real life case which shows fair result and improvement over the past studies. The model also provides some useful results which help in making more appropriate promotional policy as discussed in the result and discussion section of the paper.

There is much scope for further research, such as studies related to the impact of price change, competition, technological generations, etc. on the product diffusion. Timing studies related to new product introduction, time lag models between diffusion and adoption, diffusion of consumable goods and many more. 


\section{References}

Aggarwal, S.; Gupta, A.; Singh, Y.; Jha, P. C. 2012. Optimal duration and control of promotional campaign for durable technology product, in Proc. of the IEEE International Conference on Industrial Engineering and Engineering (IEEE IEEM -2012), 10-13 December, 2012, Hong Kong, China, 2287-2291.

Bass, P.; Bass, F. M. 2004. IT waves: two completed generational diffusion models: Working Paper. 32 p.

Bass, F. M. 1969. A new product growth model for consumer durables, Management Science 15(5): 215-227. http://dx.doi.org/10.1287/mnsc.15.5.215

Bass, F. M.; Krishnan, T. V.; Jain, D. C. 1994. Why the Bass model fits without decision variables?, Marketing Science 13(3): 203-223. http://dx.doi.org/10.1287/mksc.13.3.203

Bayus, B. L.; Jain, S.; Rao, A. G. 1997. Too little, too early: introduction timing and new product performance in the personal digital assistant industry, Journal of Marketing Research 34(1): 50-63. http://dx.doi.org/10.2307/3152064

Berry, T.; Wilson, D. 2001. On target: the book on marketing plans. $2^{\text {nd }}$ ed. Palo Alto Software Inc. 356 p.

Bridges, E.; Yim, C. K.; Briesch, R. A. 1995. A high-tech product market share model with customer expectations, Marketing Science 14(1): 61-81. http://dx.doi.org/10.1287/mksc.14.1.61

Bohlmann, J. D.; Calantone, R. J.; Zhao, M. 2010. The effects of market network heterogeneity on innovation diffusion: an agent-based modeling approach, Journal of Product Innovation Management 27(5): 741-760. http://dx.doi.org/10.1111/j.1540-5885.2010.00748.x

Burrato, A.; Grosset, L.; Viscolani, B. 2006. Advertising a new product in segmented market, European Journal of Operational Research 175(2): 1262-1267. http://dx.doi.org/10.1016/j.ejor.2005.06.035

Chandrasekaran, D.; Tellis, G. J. 2007. A critical review of marketing research on diffusion of new products, in Malhotra, N. K. (Ed.). Review of marketing research. Armonk, NY: M. E. Sharpe, 39-80.

Chatterjee, R.; Eliashberg, J. 1990, The innovation diffusion process in a heterogeneous population: a micro modeling approach, Management Science 36(9): 1057-1079. http://dx.doi.org/10.1287/mnsc.36.9.1057

Calantone, R. J.; Di Benedetto, C. A. 2000, Performance and time to market: accelerating cycle time with overlapping stages, IEEE Transactions Engineering Management 47(2): 232-244. http://dx.doi.org/10.1109/17.846790

Danaher, P. J.; Hardie, B. G. S.; Putsis, W. P. 2001. Marketing-mix variables and the diffusion of successive generations of a technological innovation, Journal of Marketing Research 38(4): 501-514. http://dx.doi.org/10.1509/jmkr.38.4.501.18907

Desiraju, R.; Nair, H.; Chintagunta, P. 2004. Diffusion of new pharmaceutical drugs in developing and developed nations, International Journal of Research in Marketing 21(4): 341-357. http://dx.doi.org/10.1016/j.ijresmar.2004.05.001

Easingwood, C.; Mahajan, V.; Muller, E. 1983. A non-uniform influence innovation diffusion model of new product acceptance, Marketing Science 2(3): 273-295. http://dx.doi.org/10.1287/mksc.2.3.273

Egan, J. 2007. Marketing communications. London: Thomson Publishing. 467 p.

Foulquie, P. C.; Munuera-Alemán, J. L.; Rodríguez-Escudero, A. I. 2004. Criteria employed for go/no-go decisions when developing successful highly innovative products, Industrial Marketing Management 33(4): 307-316. http://dx.doi.org/10.1016/S0019-8501(03)00080-4

Gupta, S.; Jain, D. C.; Sawhney, M. S. 1999. Modeling the evolution of markets with indirect network externalities: an application to digital television, Marketing Science 18(3): 396-416. http://dx.doi.org/10.1287/mksc.18.3.396

Goldenberg, J.; Oreg, S. 2007. Laggards in disguise: resistance to adopt and the leapfrogging effect, Technological Forecasting and Social Change 74(8): 1272-1281. http://dx.doi.org/10.1016/j.techfore.2006.11.001

Hauser, J.; Tellis, G. J.; Griffin, A. 2006. Research on innovation: a review and agenda for marketing science, Marketing Science 25(6): 687-717. http://dx.doi.org/10.1287/mksc.1050.0144 
Horsky, D.; Simon, L. S. 1983. Advertising and diffusion of new products, Marketing Science 2(1): 1-17. http://dx.doi.org/10.1287/mksc.2.1.1

Horsky, D.; Simon L. S. 1990. A diffusion model incorporating product benefits, price, income and information, Marketing Science 9(4): 342-385. http://dx.doi.org/10.1287/mksc.9.4.342

Ismail, K.; Leow, Y. R.; Yong, C. Y.; Abdul-Majid, I.; Thwala, W. D.; Ajagbe, M. A. 2012. Critical success factors of new product development in technology based firms: a case study, African Journal of Business Management 6(33): 9442-9451.

Jain, D. C.; Rao, C. 1990. Effect of price on the demand for durables: modeling, estimation and findings, Journal of Business and Economic Statistics 8(2): 163-170. http://dx.doi.org/10.2307/1391978

Jain, D. C. 1990. Marketing mix effects on the diffusion of innovations, Marketing Science Conference, 22-25 March, 1990, University of Illinois, Urbana-Champaign.

Jayaram, J.; Narasimhan, R. 2007. The influence of new product development competitive capabilities on project performance, IEEE Transactions of Engineering Management 54(2): 241-256. http://dx.doi.org/10.1109/TEM.2007.893992

Jha, P. C.; Gupta, A.; Kapur, P. K. 2006. Bass model revisited, Journal of Statistics and Management Systems 11(3): 413-437. http://dx.doi.org/10.1080/09720510.2008.10701320

Jha, P. C.; Aggarwal, S.; Gupta, A.; Kumar, U. D.; Kannan, G. 2014. Innovation diffusion model for a product incorporating segment-specific strategy and the spectrum effect of promotion (in Press).

Jones, J. M.; Ritz, C. J. 1991. Incorporating distribution into new product diffusion models, International Journal of Research in Marketing 8(2): 91-112. http://dx.doi.org/10.1016/0167-8116(91)90018-3

Kalish, S. 1985. A new product adoption model with pricing, advertising and uncertainty, Management Science 31(12): 1569-1585. http://dx.doi.org/10.1287/mnsc.31.12.1569

Kauffman, R. J.; Techatassanasoontorn, A. 2005. International diffusion of digital mobile technology: a coupled-hazard state based approach, Information Technology and Management 6(3): 253-292. http://dx.doi.org/10.1007/s10799-005-5882-3

Kim, N.; Chang, D. R.; Shocker, A. D. 2000. Modeling intercategory and generational dynamics for a growing information technology industry, Management Science 46(4): 496-512. http://dx.doi.org/10.1287/mnsc.46.4.496.12059

Kim, S. K.; Lee, B. G.; Park, B. S.; Oh, K. S. 2011, The effect of R\&D, technology commercialization capabilities and innovation performance, Technological and Economic Development of Economy 17(4): 563-578. http://dx.doi.org/10.3846/20294913.2011.603481

Krishnan, T. V.; Suman, A. T. 2009. International diffusion of new products, in Kotabe, M.; Helsem, K. (Eds.). The Sage handbook of international marketing. London: Sage Publication, 325-345. http://dx.doi.org/10.4135/9780857021007.n16

Kock, A.; Gemunden, H. G.; Salomo, S.; Schultz, C. 2011. The mixed blessings of technological innovativeness for the commercial success of new products, Journal of Product Innovation Management 28(S1): 28-43. http://dx.doi.org/10.1111/j.1540-5885.2011.00859.x

Kossinets, G.; Watts, D. J. 2006. Empirical analysis of an evolving social network, Science 311(5757): 88-90. http://dx.doi.org/10.1126/science.1116869

Libai, B.; Muller, E.; Peres, R. 2009. The influence of within-brand and cross-brand word of mouth on the growth of competitive markets, Journal of Marketing 73(2): 19-34. http://dx.doi.org/10.1509/jmkg.73.3.19

Mahajan, V.; Muller, E. 1996. Timing, diffusion, and substitution of successive generations of technological innovations the IBM mainframe case, Technological Forecasting and Social Change 51(2): 109-132. http://dx.doi.org/10.1016/0040-1625(95)00225-1

Mahajan, V.; Muller, E.; Bass, F. M. 1990. New product diffusion models in marketing: a review and directions for research, Journal of Marketing 54(1): 1-26. http://dx.doi.org/10.2307/1252170 
Mahajan, V.; Muller, E.; Wind, J. 2000. New product diffusion models. New York: Kluwer Academic Publishers. 355 p.

Mahajan, V.; Peterson, R. A. 1978. Innovation diffusion in a dynamic potential adopter population, Management Science 24(15): 1589-1597. http://dx.doi.org/10.1287/mnsc.24.15.1589

Mahajan, V.; Peterson, R. A. 1985. Models for innovation diffusion. California: Sage Publications. 87 p.

Meade, N.; Islam, T. 2006. Modeling and forecasting the diffusion of innovation - a 25 year review, International Journal of Forecasting 22(3): 519-545. http://dx.doi.org/10.1016/j.ijforecast.2006.01.005

Ozer, M.; Cebeci, U. 2010. The role of globalization in new product development, IEEE Transactions Engineering Management 57(2): 168-180. http://dx.doi.org/10.1109/TEM.2009.2025492

Rangaswamy, A.; Gupta, S. 2000. Innovation adoption and diffusion in the digital environment: some research opportunities. Boston: Kluwer Academic. $35 \mathrm{p}$.

Rao, K. R. 2011. Services marketing. $2^{\text {nd }}$ ed. Noida: Dorling Kindersley (India) Pvt. Ltd. 584 p.

Redmond, W. 1994. Diffusion at sub-national levels: a regional analysis of new product growth, Journal of Product Innovation Management 11(2): 201-212. http://dx.doi.org/10.1016/0737-6782(94)90003-5

Renana, P.; Eitan, M.; Vijay, M. 2010. Innovation diffusion and new product growth models: a critical review and research directions, International Journal of Research in Marketing 2(27): 91-106.

Renko, H. Y.; Janakiraman, R. 2008. How customer portfolio affects new product development in technology based entrepreneurial firms, Journal of Marketing 72(5): 131-148. http://dx.doi.org/10.1509/jmkg.72.5.131

Rogers, E. M. 1983. Diffusion of innovations. $3^{\text {rd }}$ ed. New York: The Free Press. 453 p.

Russell, T. 1980. Comments on the relationship between diffusion rates, experiences curves and demand elasticities for consumer durable technological innovations, Journal of Business 53(3): 69-78. http://dx.doi.org/10.1086/296100

Sawng, Y. W.; Kim, S. H.; Lee, J.; Oh, Y. S. 2011. Mobile service usage behavior in Korea: an empirical study on consumer acceptance of innovative technologies, Technological and Economic Development of Economy 17(1): 151-173. http://dx.doi.org/10.3846/13928619.2011.557859

Schimmoeller, L. J. 2010. Success factors of new product development processes, Advances in Production Engineering \& Management 5(1): 25-22.

Schneider, J.; Hall, J. 2011. Why most product launches fail, Harvard Business Review 89: 21-24.

Shane, S. A.; Ulrich, K. T. 2004. Technological innovation, product development, and entrepreneurship, Management Science 50(2): 133-144. http://dx.doi.org/10.1287/mnsc.1040.0204

Steffens, P. R. 1998. Applying diffusion models with regional heterogeneity, Marketing Letters 9(4): 361-369. http://dx.doi.org/10.1023/A:1008041517592

Steffens, P. R. 2002. A model of multiple ownership as a diffusion process, Technological Forecasting and Social Change 70(2): 901-917.

Stremersch, S.; Tellis, G. J.; Franses, P. H.; Binken, J. L. G. 2001. Indirect network effects in new product growth, Journal of Marketing 71(3): 52-74. http://dx.doi.org/10.1509/jmkg.71.3.52

Tolba, A. H.; Mourad, M. 2011. Individual and cultural factors affecting diffusion of innovation, Journal of International Business and Cultural Studies 5(3): 203-218. http://dx.doi.org/10.1504/IJTMKT.2010.039033

Van den Bulte, C.; Stremersch, S. 2004. Social contagion and income heterogeneity in new product diffusion: a meta-analytic test, Marketing Science 23(4): 530-544. http://dx.doi.org/10.1287/mksc.1040.0054 
Sugandha AGGARWAL obtained her MPhil and MSc degrees in the Operational Research from University of Delhi, Delhi, India in 2011 and 2009 respectively. She is presently pursuing her PhD from University of Delhi. Her research interests include modelling and optimization in marketing and soft computing.

Anshu GUPTA obtained her PhD, MPhil and MSc degrees in Operational Research from University of Delhi, Delhi, India in 2009, 2005 and 2003 respectively. She is currently working with School of Business, Public Policy and Social Entrepreneurship, Dr Ambedkar University, Delhi, India. She is a gold medallist in the Master's Degree, 2003. She has published several papers in the area of Software Reliability and Marketing. Her research interests include modelling and optimization in software reliability and marketing.

Kannan GOVINDAN is currently an Associate Professor of Operations and Supply Chain Management in the Department of Business and Economics, University of Southern Denmark, Odense M, Denmark. He has published more than 80 papers in refereed international journals and more than 70 papers in conferences. He received a gold medal for Best PhD Thesis. His research interests include logistics, supply chain management, green and sustainable supply chain management, reverse logistics and maritime logistics.

P. C. JHA obtained his PhD, MPhil and MA degrees in Operational Research from University of Delhi, Delhi, India in 2004, 1988 and 1986 respectively. He is an Associate Professor in the Department of Operational Research, University of Delhi. He has also co-authored a book Software Reliability Assessment with OR Applications, published by Springer. He has published more than 45 research papers in the areas of software reliability, marketing and optimization in Indian \& international journals and edited books. His research interests include modelling and optimization in software reliability, marketing and supply chain management.

Ieva MEIDUTĖ. Assoc. Prof., Dr of Technological Sciences (Transport Engineering), Vilnius Gediminas Technical University, Faculty of Business Management, Department of Business Technologies. Her research interests are related with business processes management, logistics and supply chain management. 